Article

\title{
Investigating Willingness to Pay to Improve Water Supply Services: Application of Contingent Valuation Method
}

\section{Kamshat Tussupova ${ }^{1,2, *}$, Ronny Berndtsson ${ }^{1}$, Torleif Bramryd ${ }^{3}$ and Raikhan Beisenova ${ }^{2}$}

1 Water Resources Engineering \& Center for Middle Eastern Studies, Lund University, P.O. Box 118, SE-22100 Lund, Sweden; E-Mail: ronny.berndtsson@tvrl.1th.se

2 Environmental Management and Engineering, L.N. Gumilyov Eurasian National University, Munaitpasov str.13,010008 Astana, Kazakhstan; E-Mail: raihan_b_r@mail.ru

3 Environmental Strategy, Lund University, P.O. Box 882, SE-251 08 Helsingborg, Sweden; E-Mail: torleif.bramryd@ism.lu.se

* Author to whom correspondence should be addressed; E-Mail: kamshat.tussupova@tvrl.lth.se; Tel.: +46-46-222-8101.

Academic Editor: Miklas Scholz

Received: 22 April 2015 / Accepted: 8 June 2015 / Published: 19 June 2015

\begin{abstract}
Safe water supply is one of the important Millennium Goals. For development of market water supply services, the willingness of consumers to pay is essential. The consumers' willingness to pay (WTP) for piped water supply using the contingent valuation (CV) method with different starting point bids was investigated for the Pavlodar Region, Kazakhstan. The results showed that households with access to groundwater (well or borehole water users) perceived this as of good quality. Consumers without access to groundwater used open-source, standpipe or delivered water for which they had to travel and spend time or to pay. Open source water and standpipe water quality was perceived as bad or satisfactory. More than $90 \%$ of the consumers were willing to pay for better water quality and regular water supply. The mean WTP was estimated to be about 1120 in bids and about $1590 \mathrm{KZT}$ per household per month in open-ended question format (150 KZT is $\sim 1$ USD as of January 2012). The results can be used to better identify the proper technological choice and the level of service to be provided making rural water projects both sustainable and replicable at a larger scale.
\end{abstract}

Keywords: willingness to pay; rural water supply; contingent valuation method; Kazakhstan 


\section{Introduction}

\subsection{Background}

Kazakhstan is a former Soviet Republic that is transitioning from state planned to market economy. This transition is changing patterns of basic services such as water and sanitation. The Soviet Union sought to tackle the desperate living conditions that the major part of the population suffered from in the early twentieth century by expanding access to essential services such as piped water. However, when the Soviet Union broke apart in 1991, many people, especially in rural areas that historically have been disadvantaged, still had limited access to drinking water. Since then, the situation has not improved much. Important elements of the state apparatus have been dismantled, leading to shortages of basic goods and services while the economic crisis has reduced funds that could otherwise have been used to invest in basic infrastructure for water and sanitation. During the transition from a state planned to a market economy, existing water supply systems have deteriorated due to lack of maintenance [1,2].

Recent research has shown that there have been no significant changes in patterns of access to piped cold water in rural and urban areas of Kazakhstan during the last 10-year period [3]. In rural areas, the access to piped cold water remains at a constant $29 \%$, although the economic situation of people has improved. Roberts et al. [3] found that respondents with stated bad to very bad economic situations changed from $24 \%$ to $7 \%$ and good to very good economic situations changed from $16 \%$ to $32 \%$ between 2001 and 2010. Consequently, the perceived improved economic situation of the households has not changed the access to piped-water in rural Kazakhstan and there is still a gap between rural and poorer households compared to urban households. These results are surprising since a massive state-run drinking water program has supposedly financed provision of drinking water to rural areas since 2002 (UNDP, 2004).

A survey made in 2005 (UNDP, 2006) showed that people in Kazakhstan have a strong incentive to pay for water and, in particular, for improved water supply and water quality. However, the survey also showed that the interviewees did not know how much this service should cost. A large part of the respondents (27\%) who expressed willingness to pay (WTP) for improved water quality could not define the maximum amount they would be willing to pay. Individuals unwilling to pay saw no problem with water supply, could not afford extra costs, or believed that the state should cover such costs [4].

If rural water projects are to be sustainable and replicable, an improved planning methodology is required that includes a procedure for eliciting information on the value placed on different levels of service. Also, tariffs must be designed so that at least operation and maintenance costs can be recovered [5]. The importance of the concept of WTP for water in rural areas has been understood for some time. The WTP is a measure of the maximum amount that a person would be willing to pay for a service rather than do without it.

In view of the above, the Kazakhstan authorities have incentive to provide a better water supply to rural families, e.g., by attracting the private sector into the field. However, to expedite the process and to make it more efficient, customers' opinion and their WTP for improved water services should be studied. Thus, the study had two main objectives. First, to test the contingent valuation (CV) method using open-ended and bids format questions with different starting points to identify the WTP for 
maintenance of the piped water system. Second, to investigate and quantify rural peoples' WTP for (individual and standpipe) piped water connection and maintenance cost.

\subsection{Review of Contingent Valuation (CV) Method}

The Contingent Valuation (CV) is one of the commonly used methods by economists, policy makers, and water utility organizations to improve water supply [6]. It has been implemented in many different water supply and sanitation projects and particularly in rural water supply, both in developed and developing countries [7-10]. Griffin (1995) compared the results of the CV survey and actual outcome three years later. He found that $15 \%$ of households got connected to piped water as compared to $15 \%$ predicted [11]. This shows that CV is reliable once it is designed and administered properly. The World Bank has been the prime user of CV in testing, and subsequently promoting, the use of the method to assess the demand for water and sanitation services in both rural and urban locations [6]. Department for International Development (DFID) is also moving towards the use of $\mathrm{CV}$, particularly to guide tariff structuring on large capital investments. The DFID Manual states that "Choice of the right technique depends on the size and complexity of the proposed program and the existing capacity in the community for self appraisal. If resources are available, the Contingent Valuation Method is the most reliable" [12].

The CV uses hypothetical data to estimate the ex-ante WTP. The strength of the method is its flexibility [13]. It can be used to construct realistic policy scenarios for most new policies. Another strong point is the ability to measure non-use values. The main weakness of the method is its hypothetical nature. Respondents can sometimes find themselves in unfamiliar situations in which complete information is not available. At best, respondents may give truthful answers that are limited by their unfamiliarity. At worst, respondents may give trivial answers due to the hypothetical nature of the scenario [13]. There are three obstacles that should be considered when using CV: (1) Proper administration and execution of the CV survey; (2) proper conducted CV scenario; and (3) reliability of the key assumptions, where results can be robust with respect to simple variations in research design and survey method. Properly performed, the CV survey might be the most informative technique for WTP surveys [14].

One of the main problems with many CV investigations conducted in developing countries is that the surveys themselves are poorly executed. This is quite often due to poorly trained enumerators and resulting enumerator bias [14]. Economists recognize it as a principal-agent problem, in which the CV researcher (principal) typically does not know the enumerator (agent) before the survey. It is crucial that the enumerator does not have influence on the answers of interviewees, such as to see his/her role as an educator who is to convince respondents that they should be willing to pay for the service offered, or to "improve" the CV scenario in any way. Even the best CV scenario may make little sense to an interviewee if the enumerator does not pose the question in a relevant manner [14].

A constraint using the $\mathrm{CV}$ method may be that respondents do not face a real economic choice. Developing a relevant CV scenario means to pose a short explanation of the problem and then present a logical choice for the respondent. It implies a better connection between the CV scenario and the selection of the elicitation procedure. There are several elicitation procedures and the effect of these methods upon WTP may be large. Open-ended maximum WTP valuation question and closed ended, yes/no valuation question are often discussed in contemporary research. Open-ended questions mean 
that the respondent is asked to give a maximum price for the offered hypothetical good or service. Closed-ended questions mean that yes or no is used for an already defined price and the respondent should either accept or reject it.

In order to better understand the reaction of the respondent to a CV scenario and the elicitation procedure, the importance of carrying out a variety of split-sample experiments has been stressed in the literature $[15,16]$. There are two main reasons for conducting split-sample experiments in CV research designs. The first is that the $\mathrm{CV}$ researcher almost always faces some difficult choices in the study design with respect to the development of the $\mathrm{CV}$ scenario and elicitation procedure. Second, performing a $\mathrm{CV}$ survey provides an opportunity to learn more about possible procedures in terms of alternative research design choices in different cultures [14].

\section{Experimental Area and Methodology}

\subsection{Area Description and Drinking Water Sources}

The Pavlodar area is one of 14 regions in Kazakhstan. It is situated in the northeast of the country in the Irtysh River Basin. The area has three cities and 412 rural districts. The rural districts have a population of about 270,000 people. The steppe comprises the greatest portion of the region. The climate is highly continental, relatively dry with large temperature amplitude (about $-40{ }^{\circ} \mathrm{C}$ to $+40{ }^{\circ} \mathrm{C}$ ), a long and cold winter (5.5 months) and a short and hot summer ( 3 months). This very large intra-annual temperature variations limit the regional water resources that mainly depend on the snowmelt.

The scant precipitation has an uneven distribution within the territory and within the seasons. Up to $80 \%$ of annual precipitation fall during the summer period. Most of the rainfall ends up as soil moisture and evapotranspiration. Average annual Class A pan evaporation is about $800 \mathrm{~mm}$. The available water resources of the region are mainly the Irtysh River and groundwater. Smaller rivers usually have a short spring discharge before they dry up.

Main water supply systems can be classified as centralized and decentralized. The main difference is that centralized water supply has a distribution system to provide water from the natural water source with or without treatment to the water user, while decentralized water supply system uses water directly from the water source with or without treatment. Consequently, centralized water supply generally means water provided through pipes to households (tap water) and public standpipes. Protected boreholes, wells, and springs are considered to be decentralized water supply sources. Centralized and decentralized systems can be either private or public. Both groundwater and surface water may be used for the centralized systems. However, groundwater is the most common type for rural centralized systems in the region.

\subsection{Survey Design}

The survey was performed between October 2011 and January 2012, in eleven villages of Pavlodar region. In total, 168 questionnaires were completed and included in the survey analysis. Since the villages are of different sizes, each household was chosen randomly so that at least half of the respondents would live in four different directions outside of the central part of the village. 
Face-to-face interviews with the heads of households were conducted in the respondents' homes. Standardized questions regarding socio-economic and demographic characteristics, existing drinking water sources and their characteristics, trust to water management types, and direct open-ended and bids questions on WTP were used.

The study adopted both stated preference and revealed preference methods to value the existing and hypothetical water supply service. For stated preference approach, the CV method was used where respondents were directly asked about their WTP for the piped water system. The question asked was: How much is your household willing to pay monthly for the maintenance of a private connection and $24 \mathrm{~h}$ a day access to potable water?

For the revealed preference approach, averting behavior method was used. The averting behavior method begins with the recognition that individuals seek to protect themselves when faced with environmental risk such as contaminated drinking water [17,18]. The questions asked were: (1) What is your main drinking water source? Is your water source private or public? (2) How do you assess your drinking water quality: turbidity, odor and taste in a scale — bad, satisfactory or good? Are there visible suspended particles in the water? Perceived water quality was assessed as acceptable or bad based on the answers. If the answer is "bad", or there is a visible suspended particle in the water, then the quality is "bad", otherwise "acceptable"; (3) Do you treat (boil, filter or other) your water before drinking? Do you use bottled water or get water from a local treatment point?

The CV method was used to identify WTP for individual water connection and public standpipe. One scenario was developed for all categories of water users depending on respondents' answer to type of water source that they are using. If they do not use standpipe and do not have the individual connection respondents would answer how they would like to pay for one of them when connected and if the family use a standpipe or have a individual connection and how much they would like to pay for potable water available $24 \mathrm{~h}$ a day (Table 1$)$.

Across the questionnaire, two types of questions were asked. The first, open-ended, directly asked about the maximum amount(s) (s)he would be willing to pay for the proposed water supply improvement. The second was a bidding game, when households are asked different prices until settling at a maximum offered price. The reason for having these two question formats is to see whether respondents react similar regardless of type of asked question.

The split-sample experiment was incorporated into the research design; three different bidding games with different starting points were randomly assigned to respondents in the study. All three bidding games were evenly distributed among the respondents in the survey. The purpose of the split-sample experiment was to test whether respondents' WTP would be influenced by the magnitude of the first price that they received and the sequence of follow-up questions. There are two differing viewpoints on such a "starting point" test. One is that a differing starting point conveys information about the cost of the service provided. From this viewpoint, different starting points will induce different answers from the respondents. Consequently, if the split-sample test elicits different answers, one would conclude that respondents are in fact taking the $\mathrm{CV}$ scenario seriously. A second perspective is that a respondent holding the precise WTP amount in his/her mind and receiving different starting points will provide essentially the same WTP answers. If so, one would have greater confidence that they are revealing a "true" WTP [14]. 
Table 1. CV scenario and the choice of elicitation procedure.

\begin{tabular}{|c|c|c|}
\hline $\begin{array}{c}\text { Type of } \\
\text { Elicitation } \\
\text { Procedure } \\
\end{array}$ & $\begin{array}{l}\text { CV Scenario for } \\
\text { Public Standpipe }\end{array}$ & CV Scenario for Private Connection \\
\hline $\begin{array}{c}\text { Open-ended } \\
\text { maximum WTP }\end{array}$ & $\begin{array}{l}\text { If water is provided for your } \\
\text { village with public standpipes } \\
\text { on each street and unlimited } \\
\text { potable water supply at any } \\
\text { time of the day, how much } \\
\text { would your household be } \\
\text { willing to pay each month? }\end{array}$ & $\begin{array}{l}\text { Besides the use of water from the public standpipe you can } \\
\text { have private connection, that is, the water will be in your } \\
\text { house. You will not be able to sell water or use it for } \\
\text { watering the garden. If you do not pay a monthly fee, your } \\
\text { private connection will be disconnected. How much would } \\
\text { your household be willing to pay monthly for the } \\
\text { maintenance of a private connection and } 24 \mathrm{~h} \text { access to } \\
\text { potable water? }\end{array}$ \\
\hline $\begin{array}{l}\text { Closed end, } \\
\text { bidding game }\end{array}$ & $\begin{array}{l}\text { How much would your } \\
\text { household be willing to pay } \\
100,200,500,700 \text { or } 1000 \\
\text { KZT * a month for maintaining } \\
\text { the standpipe in your district? }\end{array}$ & $\begin{array}{l}\text { Suppose your household pays for the installation of } \\
\text { individual connection (taps at home) and there are already } \\
\text { public standpipes so that everyone will have at their disposal } \\
\text { good drinking water. Would your household be willing to } \\
\text { pay } 300,500,1000,1500 \text { or } 2000 \mathrm{KZT} * \text { each month to } \\
\text { have a private connection and } 24 \mathbf{h} \text { access to potable } \\
\text { water? }\end{array}$ \\
\hline
\end{tabular}

Note: * $150 \mathrm{KZT} \sim 1$ USD (as of January 2012).

In order for the CV-based estimates to be reliable, strategic and hypothetical bias sources were considered. Strategic bias will not occur or will be minor if there is no cost associated with telling the truth and little or nothing is gained if the respondent does not tell the truth. The study tried to estimate this type of bias. Two types of respondents' answers were considered; the first question was explained as a possible future project and the second was explained as a general survey without practical influence. Avoiding hypothetical bias requires the presentation of believable and familiar scenarios for the resource under consideration. One concern in water supply projects is the permanent availability of good quality water. For this reason, questions were designed as offering $24 \mathrm{~h}$ access to treated potable water distributed through the piped system.

The enumerators were specially trained students, following the principle that good enumerators make respondents feel comfortable and at ease. Therefore, the enumerator was not supposed to influence or convince the respondent's WTP by remaining quite neutral about answers. The enumerators were explained what the study was about, so that they would be able to explain what the maximum WTP is as well as to read slowly and clearly the questions.

\subsection{Data Analysis}

The collected data were used to calculate the mean WTP according to the following:

$$
\mathrm{E}[\mathrm{WTP}]=\operatorname{Pr}_{(\text {Zero })} \cdot 0+\mathrm{E}\left(W T P_{W T P>0}\right) \cdot \operatorname{Pr}_{(\text {Positive })}
$$

where

$\operatorname{Pr}_{(\text {Zero })}$ is probability that a respondent has zero WTP;

$\operatorname{Pr}($ Positive $)=1-\operatorname{Pr}($ Zero $)$ is probability that a respondent has a positive WTP; and 
$E\left(W T P_{W T P}>0\right)$ is mean WTP for the positive WTPs.

A few extreme outliers had to be excluded in the open-ended format before analyses. Due to more or less equal distribution of WTP among the bids both for standpipe and private, connection WTP was split into two categories. For private connection, low bids were between 300 and 1000 KZT and high bids were between 1500 and $2000 \mathrm{KZT}$. For standpipe connection, lower bids were 100, 300, and 500 KZT and higher bids were 700 and 1000 KZT. Binary logistic regression commands in the SPSS software were used to find the maximum likelihood estimation of the independent variables (determinants) as regards lower and higher bids (lower and higher WTP) according to:

$$
\begin{aligned}
& \ln (W T P)=\ln \left\lfloor\frac{\operatorname{Pr}}{(1-\operatorname{Pr})}\right\rfloor=a+b X \\
& {\left[\frac{\operatorname{Pr}}{(1-\operatorname{Pr})}\right]=e^{a+b X}} \\
& {\left[\frac{\operatorname{Pr}}{(1-\operatorname{Pr})}\right]=e^{a}\left(e^{b}\right)^{X}}
\end{aligned}
$$

where $a$ and $b$ are constants and $b X$ is consumer index.

\section{Results and Discussion}

\subsection{Existing Water Sources and Perceived Quality}

There are several water source types available in the region. Figure 1 shows these sources divided by the total users. One of the most used water source is a private borehole. The boreholes are generally 8 to $50 \mathrm{~m}$ deep with a diameter of 10-30 cm. Water is usually pumped by electricity and in rare cases by hand and usually covered with a plastic top. Private wells supply $18.5 \%$ of the respondents with water. Wells are dug down to about $10 \mathrm{~m}$ with a diameter of $0.5-1.5 \mathrm{~m}$. In most cases wells are covered with a wooden plain. Almost every fifth household uses delivered water that is obtained from the local treatment plant by paying a fixed amount for each five gallons of water. The price can vary between 20 to 40 KZT for five gallons (about 19 L) depending on the locality. Thirteen percent of respondents use water from an open source, which is taken from the river either directly by the households or delivered from the source for payment. Standpipe water is usually groundwater distributed through pipes and obtained from a standpipe. Only few households (4\%) use water from the centralized system and have tap water at home. Groundwater is the main source of water for the centralized piped system. All water users, except those who use open sources, can drink their water without pre-treatment and only those who use open source have mechanical treatment and boil their drinking water.

Totally, nine persons have tap water at home, out of these six have water from the centralized system, and three have constructed by themselves taps at home and take water from wells and boreholes.

Figure 1 shows the perceived water quality depending on water source. The overall satisfaction with the water quality is $67 \%$. The most satisfied with the quality of water are borehole water users and the least satisfied with the quality of water are those who use water directly from the river. 

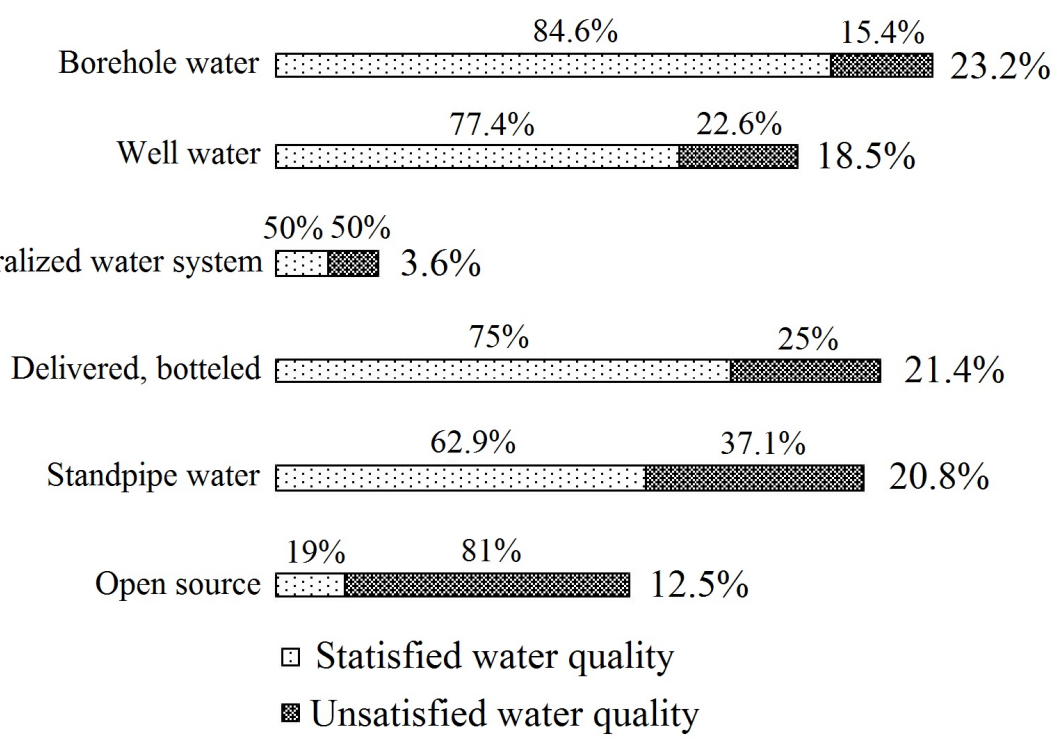

Figure 1. Drinking water users' perception of water quality.

\subsection{Willingness to Be Connected to the Piped Water System}

Respondents were asked about their willingness to be connected to the piped water system and pay 20,000 KZT ( 133 USD) as a connection fee. In total, seven persons do not want to be connected at all and one person does not know. Thus, 160 households are willing to be connected and out of these $60 \%$ are ready to pay a connection fee. About $83 \%$ of households would like to have a water meter and pay according to the actual volume used. The rest would like to pay a fixed amount per month and household. Since the piped water system includes a standpipe within the village, the question about the responsibility for the maintenance of the piped water system and standpipes was included. About $75 \%$ of the respondents believe that the government should take the responsibility for maintaining the piped water system while $15 \%$ of the respondents find it is the user's responsibility. The rest would like to rely on a private or profit organization.

\subsection{WTP for Open-Ended Question and Bids Format}

Two types of question formats were used to identify peoples' WTP: open-ended question format and bids format. In total, for private connection and standpipe, 160 questionnaires were used. These correspond to those who would like to be connected to the water supply system. Figure 2 shows the reduction of "I don't know" answers in bids format in both standpipe and private connections. For standpipes, there were even some changes of mind from "zero" payment to some payment from open-ended to bids format. Those who were not sure in the open-ended question format after bids prices preferred to pay nothing for private connection. Thus, this increased the number of respondents from seven in open-ended format to 10 in the bidding game. The bids question type gives higher response rates.

Figure 3 shows that the mean value for both connections in open-ended and bids format differs significantly. Mean value for open-ended format was $1587 \mathrm{KZT}$ and for bids format $1117 \mathrm{KZT}$ for private connection. The median was, however, almost the same, indicating that at least half of the households are willing to pay up to $1000 \mathrm{KZT}$. Both mean and median WTP were different for standpipe connection in open-ended and bids formats. Still, it is not surprising that mean WTPs were different 
since the range of the price in both bids was fixed and those with a high WTP in open-ended question may simply give a higher than maximum offered price in bids format.

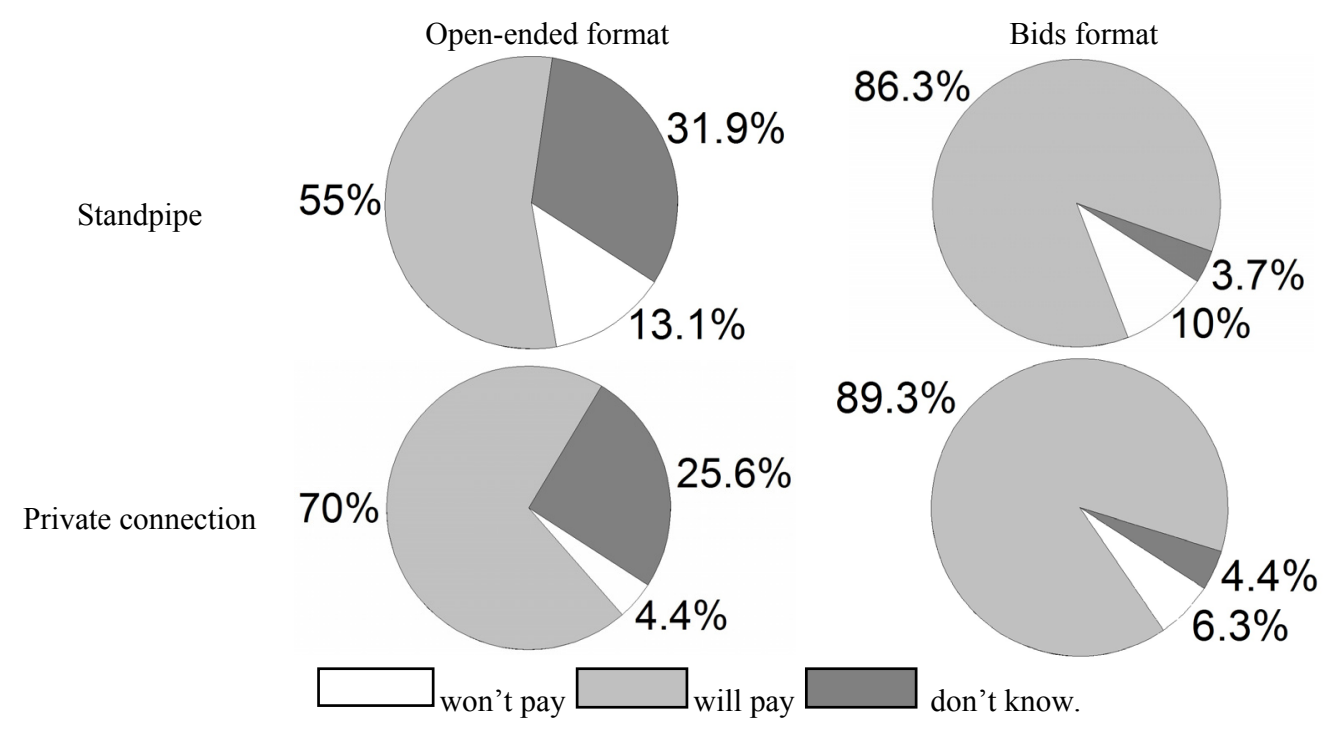

Figure 2. Answer rate to open-ended and bids format questions for standpipe and private connection, respectively.

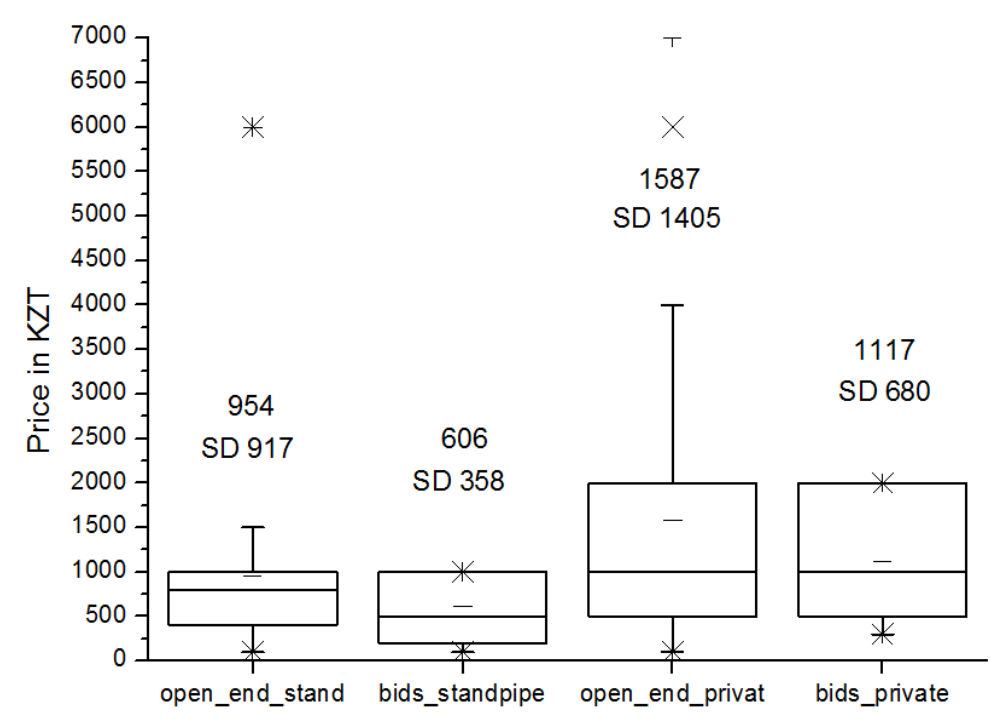

Figure 3. Boxplot of WTP for open-ended and bids answers both private connection and standpipe water $(\mathrm{SD}=$ standard deviation $)$.

A paired sample $t$-test was conducted to compare the mean values for both open-ended and bids format questions excluding all values above 2000 in open-ended format and "zero" answers in both (Table 2). This test was carried out to see whether those who give some price in open-ended question give similar answer in bids format. Table 2 shows that there is no significant difference between both groups for private connection and standpipe. This indicates that both methods can be used if ranged within some amount. An advantage of the bids format is a larger response rate. 
Table 2. Comparing means for open-ended and bids format standardized from 100 to 2000.

\begin{tabular}{ccccccc}
\hline & \multicolumn{2}{c}{ Public Standpipe } & & \multicolumn{2}{c}{ Private Connection } \\
\cline { 2 - 3 } \cline { 5 - 6 } & Open-Ended & Bids & & Open-Ended & Bids \\
\hline Mean & 607 & 588 & & 1110 & 1089 \\
SD & 329 & 354 & & 637 & 667 \\
t-statistics & \multicolumn{2}{c}{$0.5 *$} & & & \multicolumn{2}{c}{$0.3 *$} \\
DF & \multicolumn{2}{c}{65} & & \multicolumn{2}{c}{88} \\
Prob. & \multicolumn{2}{c}{0.6} & & 0.8 \\
\hline Note: * At the level 0.05 the difference of population means is not significantly different.
\end{tabular}

All WTPs above $2000 \mathrm{KZT}$ in private connection and above $1000 \mathrm{KZT}$ in standpipe connection in open-ended format were compared with the answers from the bids format to see whether respondents would give the same answer for open-ended question by giving the maximum offered in the bids format. In open-ended format for standpipe water $70 \%$, and for private connection $77 \%$, of respondents would pay the highest offered amount in the bids and about $30 \%$ and $23 \%$, respectively, would pay lower than offered maximum amount in the bids format. Consequently, bids format give more reliable replies. Thus, for further analyses, only answers from the bids format were used due to their higher response rate and more reliable replies.

\subsection{Testing for Strategic Bias}

To test for strategic bias, two types of narratives were used to the different respondents. For the first group of respondents, the questionnaire was for a possible future water project and for the second group it was for a research survey without any connection to real water provision. This was done to see whether people in the first group would answer strategically by overestimating or underestimating the real WTP.

For the private connection, there was no significant difference between mean WTP in the bids format (at 5\% probability level; Table 3), assuming that people did not try to influence the outcome of the project. A slight difference was noted for the mean WTP in the standpipe bid answers. Most of the current standpipe and central water supply users were in the first group and the second group households mostly using either open source or delivered water. Also, many private borehole water users were in the first group, assuming a benefit from not having to obtain water from the standpipe, especially in winter with a very cold climate. It can be concluded that overall respondents did not reply in a strategic manner.

Table 3. Test results for strategic bias.

\begin{tabular}{ccccccc}
\hline & \multicolumn{2}{c}{ Public Standpipe } & & \multicolumn{2}{c}{ Private Connection } \\
\cline { 2 - 3 } \cline { 5 - 6 } & Group 1 & Group 2 & & Group 1 & Group 2 \\
\hline Mean & 533 & 678 & & 1112 & 1123 \\
SD & 374 & 327 & & 716 & 644 \\
t-Statistics & \multicolumn{2}{c}{$-2.4 *$} & & & \multicolumn{2}{c}{$-0.09 * *$} \\
DF & \multicolumn{2}{c}{136} & & \multicolumn{2}{c}{141} \\
Prob. & \multicolumn{2}{c}{0.02} & & \multicolumn{2}{c}{0.9} \\
\hline
\end{tabular}

Notes: * At the level 0.05 the difference of population means is significantly different; ** At the level 0.05 the difference of population means is not significantly different. 


\subsection{Comparison of Bids with Different Starting Points}

Figure $4 \mathrm{a}, \mathrm{b}$ show the cumulative distribution of maximum WTP for standpipe and private connection, respectively. In both cases the bids with different starting points lead to different maximum WTP price. This means that the lower the starting point, the lower the maximum WTP price. Although, this leads to different mean value of WTP, respondents still do not react positively to the starting price. Even though there is a tendency to give a WTP bid closer to the starting point, respondents still did not directly say yes to the first offered WTP bid. Therefore, further analyses were made to decipher how different water users react towards bids with different starting prices.
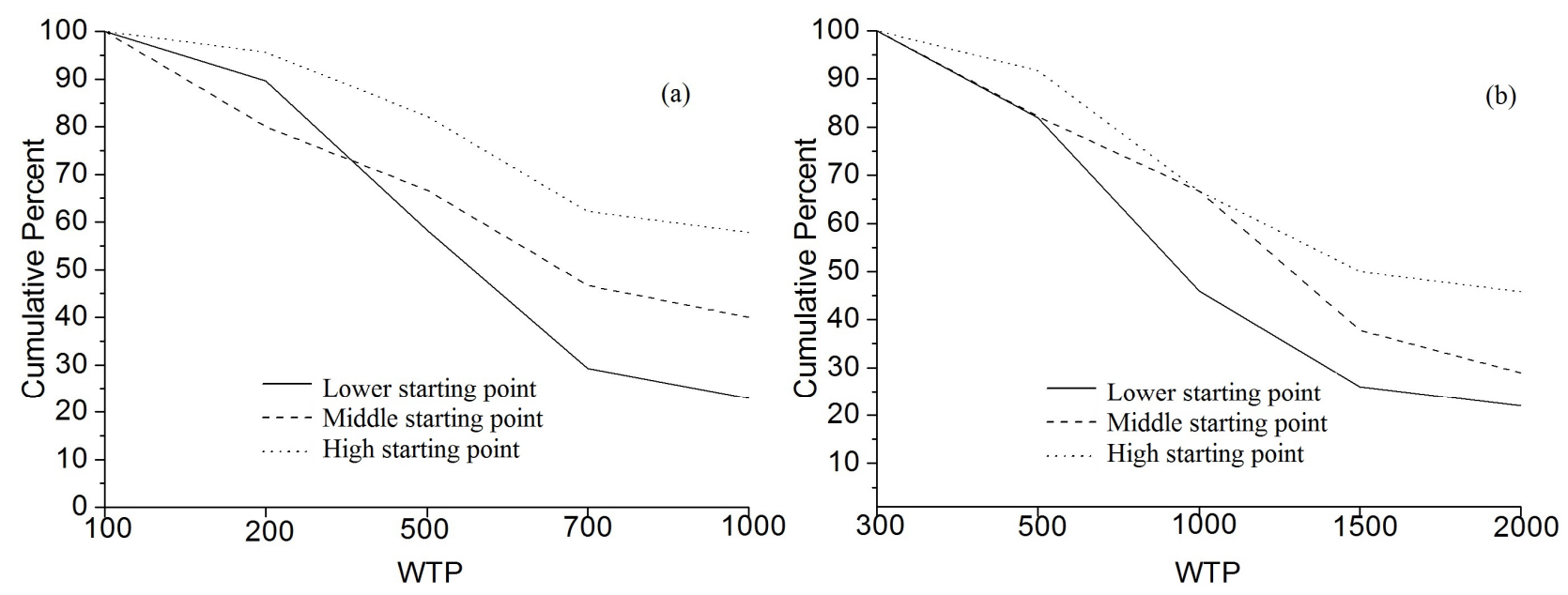

Figure 4. Cumulative distribution of maximum WTP (KZT) for standpipe (a) and private (b) connection.

Figure 5a,b shows bid distribution with lower, middle, and higher starting prices for private connection and public standpipe depending on water supply source. As seen from the figure, the respondents using different water supply sources react differently to the different bid technique. Borehole, well, and open source water users have a tendency towards the starting WTP price, but this is mostly for higher bids. For delivered and standpipe water the starting WTP price does not have a large influence. One of the reasons for this is that respondents that use delivered water and water from standpipe already have expenses compared to those who use private borehole, private wells, and water from open source. The only difference between private borehole, private well water, and open source water users is that the latter one has to spend time for the water delivery. The general tendency is that for higher WTP bids, respondents were more inclined towards the starting WTP price compared to lower and middle starting prices.

To conclude, those who already have expenses for water already have a price in mind and the bids with different starting points do not have influence on either the starting price or the mean value for each biding game with different starting point. Those who do not have current expenses for water supply are somewhat influenced by the bids leading to a different mean value in each bid with different starting price. However, respondents still considered this and did not agree on the first price. Therefore, the bids format questions for those who use borehole, well water, and open source water need to be carefully constructed for a relevant design of a future drinking water supply system. 

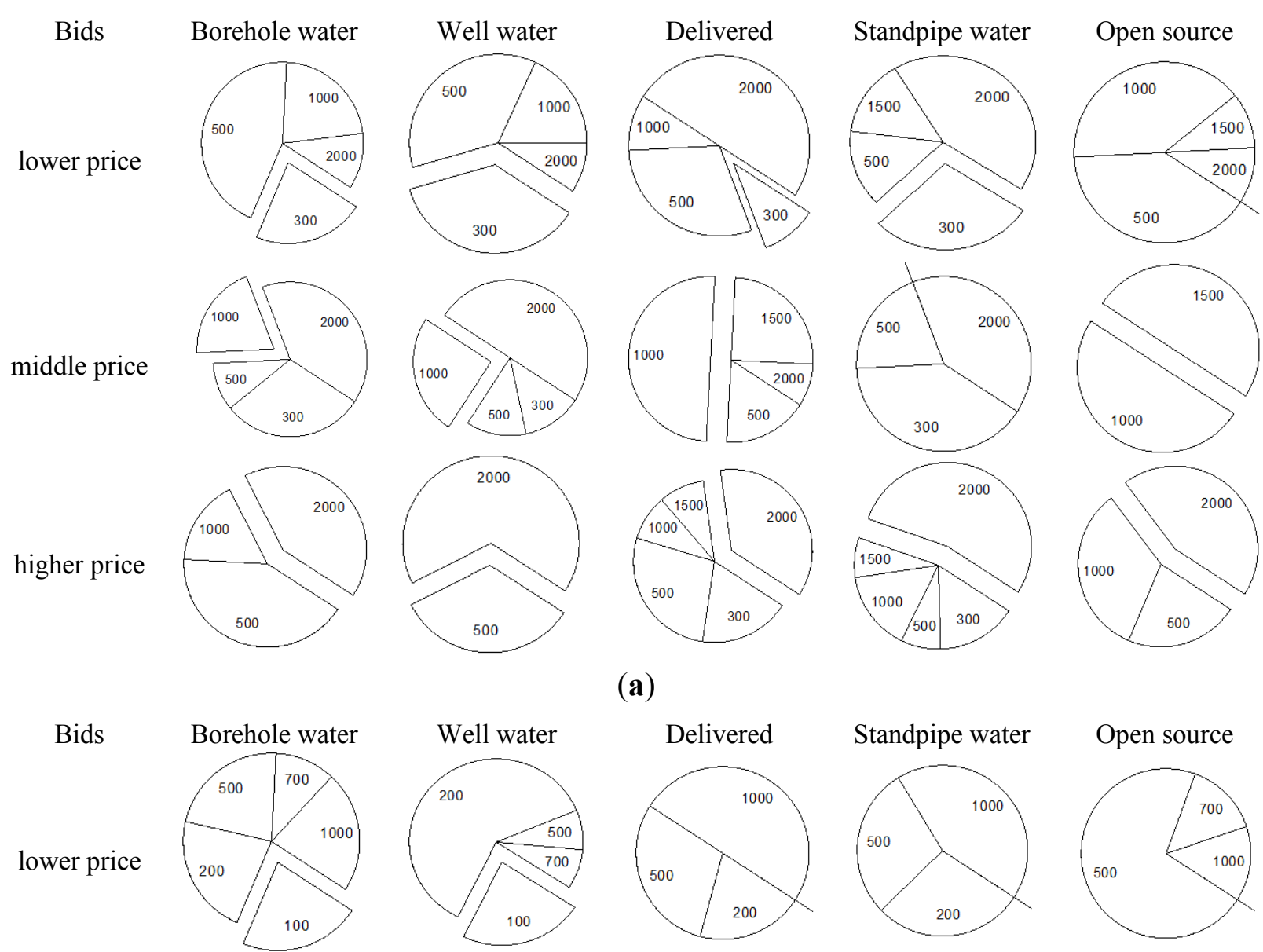

Well water

(a)

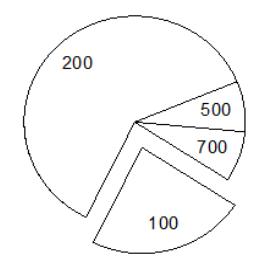

Delivered

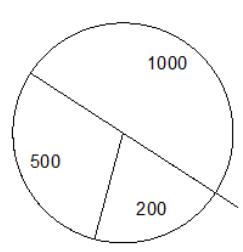

Standpipe water

Open source
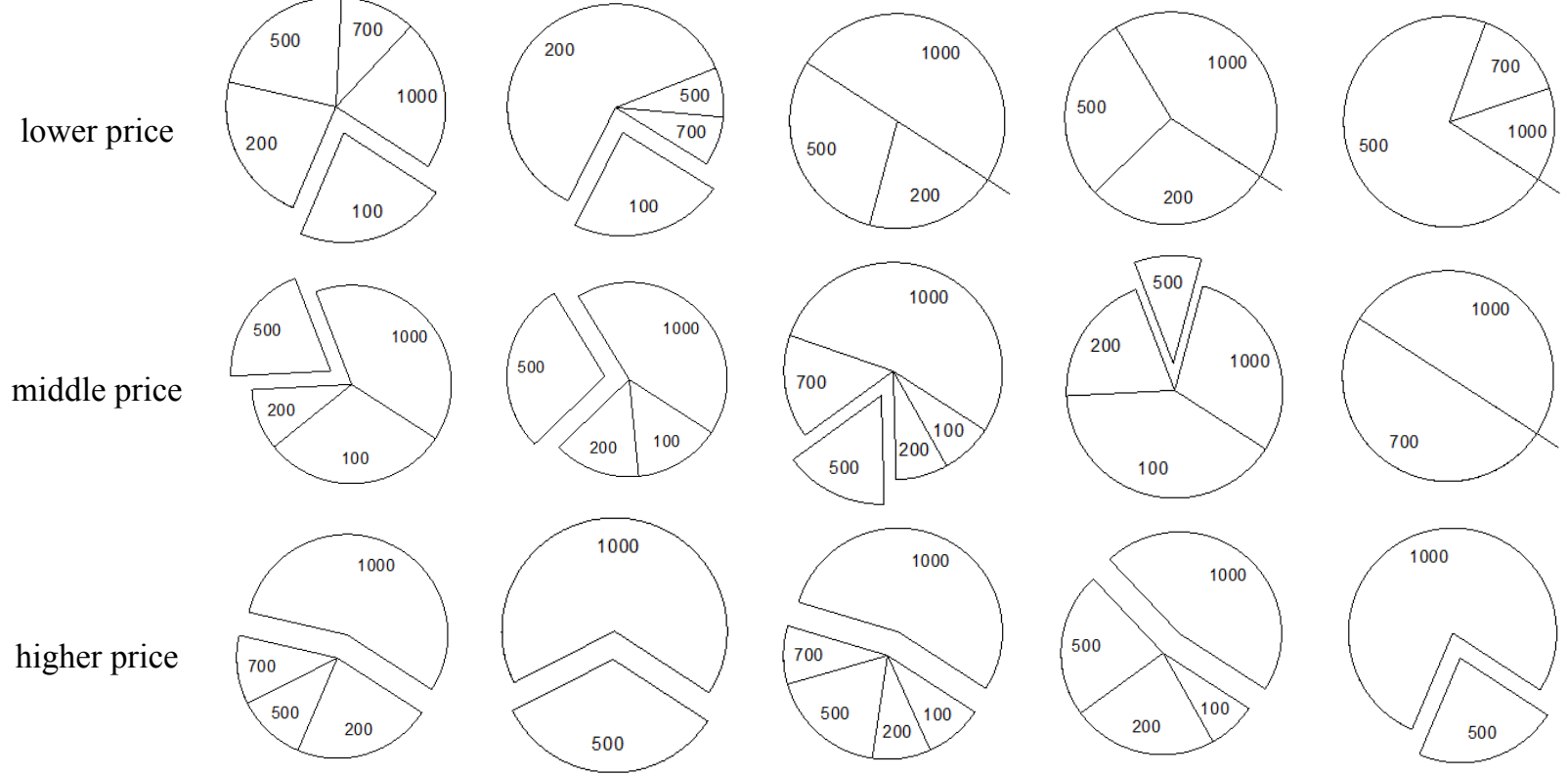

(b)

Figure 5. (a) WTP bids distribution for private connection depending on water supply type (KZT); and (b) WTP bids distribution for standpipe water depending on water supply type (KZT).

\subsection{Determinants of WTP}

The study also investigated factors that may influence respondents WTP. The descriptive statistics of these factors can found in the Appendix 1. Using a stepwise regression method, affecting variables were included into a final binary logistic model. The summary of these variables for both standpipe water and private connection are given in Tables 4 and 5. Especially, the variables water source type and payment for the connection appeared to be significant at 5\% level in both cases. Public water users, i.e., users of water from open sources and public standpipe or delivered water, are more likely to be in the higher bids 
category compared to those who use private sources such as private wells, borehole water, and centralized water supply. Private well and borehole water users represent about $95 \%$ of all private water supplies that do not have any monthly fees. These water sources are perceived as of good quality compared to the public sources such as open source and standpipe water.

Table 4. Explanatory variables of WTP for standpipe water.

\begin{tabular}{ccccccc}
\hline Variables & B & S.E. & Wald & df & Sig. & $\operatorname{Exp(B)}$ \\
\hline Sex: $0=$ woman, $1=$ man & 0.223 & 0.392 & 0.323 & 1 & 0.570 & 1.250 \\
Family with children: $0=$ no, $1=$ yes & 0.280 & 0.384 & 0.534 & 1 & 0.465 & 1.324 \\
Water source: $0=$ private, $1=$ public & 0.877 & 0.394 & 4.968 & 1 & 0.026 & 2.405 \\
Water quality: $0=$ bad, $1=$ satisfactory & 0.899 & 0.417 & 4.654 & 1 & 0.031 & 2.456 \\
Connection fee: $0=$ no, $1=$ yes & 1.146 & 0.407 & 7.922 & 1 & 0.005 & 3.146 \\
Constant & -2.300 & 0.586 & 15.401 & 1 & 0.000 & 0.100 \\
\hline
\end{tabular}

Note: Cases selected 137 Nagelkerke R Square 0.183 Significance 0.348 .

Table 5. Explanatory variables for private connection.

\begin{tabular}{ccccccc}
\hline Variables & B & S.E. & Wald & df & Sig. & $\operatorname{Exp(B)}$ \\
\hline Sex: $0=$ woman, $1=$ man & 0.447 & 0.384 & 1.350 & 1 & 0.245 & 1.563 \\
Family with children: $0=$ no, $1=$ yes & 0.828 & 0.395 & 4.390 & 1 & 0.036 & 2.289 \\
Water source: $0=$ private, $1=$ public & 0.806 & 0.398 & 4.087 & 1 & 0.043 & 2.238 \\
Water quality: $0=$ bad, $1=$ satisfactory & 0.599 & 0.414 & 2.091 & 1 & 0.148 & 1.820 \\
Connection fee: $0=$ no, $1=$ yes & 1.160 & 0.432 & 7.202 & 1 & 0.007 & 3.189 \\
Constant & -2.874 & 0.629 & 20.863 & 1 & 0.000 & 0.056 \\
\hline
\end{tabular}

Note: Cases selected 142 Nagelkerke R Square 0.191 Significance 0.005.

The connection fee can be seen as an indirect wealth indicator of a household, since occupation in the stepwise regression did not display any significance. Thus, occupation was not included into the model. Not surprisingly, those who were ready to pay a connection fee in the amount of 20,000 KZT to have a private connection at home were very frequent in the high WTP category. This can be explained by the fact that respondents may have savings without necessarily having either permanent income or garden or livestock. This may also indicate that respondents do not have proper access to water and therefore give a high priority to safe water connection. In any case, the impact of the household wealth needs to be further investigated in future surveys.

The perceived water quality was not significant for the private connection but appeared to be significant for the standpipe connection. This displays that the more respondents are satisfied with the quality of the existing water source the more they are willing to pay. This appears to be somewhat strange, but might be explained by the fact that the most satisfied respondents are mostly those who use delivered water.

The variable Households with children is statistically significant at the $5 \%$ for private connections. Respondents with children were willing to pay more on average. Obviously households with children may gain much in having access to water at home in terms of, first of all, water quantity and, if possible, water quality. This variable is not significant for standpipe connection, which is not surprising. Most respondents either use a private water source, meaning that they have water access very close to home or delivered water, and for them there is no point of paying more for standpipe water with walking and queuing for water in a limited amount. 
Although men are more frequent than women in the higher category bidding, gender is not statistically significant in either type of water source. Further analyses are needed to verify these results in comparison with age and/or occupation.

\section{Conclusions}

The paper investigated whether the CV method using bids with different starting points and open-ended format questions can be used to quantify rural peoples' WTP for improved water services. In total, $95 \%$ of the rural respondents were willing to be connected to the piped water system. Out of these, more than half were ready to pay the fee of 20,000 KZT for the individual connection. The mean WTP for the maintenance of the individual piped water system was about $1120 \mathrm{KZT}$ per month per household in the bids format and about $1590 \mathrm{KZT}$ per month per household in the open-ended format question. For public standpipe, the mean WTP was about 950 KZT per month per household in the open-ended category answers, and about 610 KZT per month per household in the bids format. When open-ended answers are adjusted up to the maximum amount in bids format, the difference of mean values are insignificant.

The response rate for the bids format was higher than for the open-ended format questions due to a huge shift in "don't know" answer in open-ended format to "some payment" in bids format. However, using bids with different starting points can thus be influential. If respondents have not paid to obtain water and have no real idea how much they should pay, then the first price is interpreted as a reference price. Private borehole and private well water users as well as open source water users were partially navigated by the first price, although the magnitude of the first price was not high. In contrast, if users are already charged and/or have to spend some time to obtain water, such as delivered water and standpipe water users, their bids with different starting point do not have significant influence. Consequently, this should be considered when implementing the survey in villages with different water sources.

The main influencing factors for high or low WTP were the existing water source and the payment of fee for the private connection. Private water users with borehole and well water do not have charges and perceive their water to be of good quality. Thus, they were willing to pay less. Those who use public sources such as open source and standpipe water were ready to pay more every month to get access to piped water, which is more convenient compared to the existing sources, as they have to travel, as well as sometimes pay, to obtain water. They perceived the water quality as not good. The readiness to pay the connection fee for private access to water as a possible indicator of the household wealth showed that those who are ready to pay the connection fee of 20,000 KZT were much more frequent in the higher bids category. The connection fee might be an implicit indicator of the household having savings and the ability to pay. However, the household wealth indicator should be well constructed in future surveys.

The obtained results can be used by water supply managers and engineers in order to better identify the proper technological choice and the level of water service to be provided. Thus, it will make rural water projects both sustainable and replicable at a larger scale.

\section{Acknowledgments}

The authors express gratitude to Roza Shamkenovna from the Department of Internal Politics, Pavlodar Oblast, for the assistance in conducting the survey and collecting the questionnaires. 


\section{Author Contributions}

The first author planned the survey design, analyzed initial results, and wrote the first version of the paper. The other authors contributed in an equal manner to the paper by adding comments and writing parts of the final paper.

\section{Conflicts of Interest}

The authors declare no conflict of interest.

\section{Appendix}

Table A1. Descriptive statistics of survey results.

\begin{tabular}{lcc}
\hline \multicolumn{1}{c}{ Description } & Percentage & Mean \\
\hline Living time for the household in the area: & & \\
\hline Less than 5 years & $8 \%$ & \\
Between 5 and 10 years & $16 \%$ & \\
$\quad$ More than 10 years & $76 \%$ & 3.9 (SD 0.28) \\
\hline Number of people in household (min. $=1$ and max. $=7$ ) & 0.32 \\
\hline Family with retired person: $1=$ yes, $0=$ no & & 0.59 \\
\hline Family with children up to 18 years old: $1=$ yes, $0=$ no & 0.84 \\
\hline Household owning either life stock or garden: $1=$ yes, $0=$ no & 0.50 \\
\hline Household owning the livestock: $1=$ yes, $0=$ no & 0.75 \\
\hline Household having a garden: $1=$ yes, $0=$ no & \\
\hline Occupation of household head or main income source in household: & \\
\hline$\quad$ Budget worker (including teacher and retired person) & $54 \%$ \\
$\quad$ Self-employed with no permanent income, including seasonal jobs & $31 \%$ & \\
$\quad$ Self-employed hiring people (relative permanent income) & $8 \%$ & \\
$\quad$ Unemployed & $7 \%$ & 0.64 \\
\hline Sex of respondent: $1=$ female, $0=$ male & & 0.57 \\
\hline Water source: $0=$ private, $1=$ public & 0.68 \\
\hline Water quality: $0=$ bad, $1=$ satisfactory & & 0.060 \\
\hline Connection fee: $0=$ no, $1=$ yes & \\
\hline
\end{tabular}

Note: $\mathrm{SD}=$ standard deviation

\section{References}

1. McKee, M.; Balabanova, D.; Akingbade, K.; Pomerleau, J.; Stickley, A.; Rose, R.; Haerpfer, C. Access to water in the countries of the former Soviet Union. Public Health 2006, 120, 364-372.

2. OECD EAP Task Force. Financing Water Supply and Sanitation in Eastern Europe, Caucasus and Central Asia; Organization for Economic Co-operation and Development (OECD): Paris, France, 2006.

3. Roberts, B.; Stickley, A.; Gasparishvili, A.; Haerpfer, C.; McKee, M. Changes in household access to water in countries of the former Soviet Union. J. Public Health 2012, 34, 352-359.

4. United Nations Development Programme (UNDP). Access to Drinking Water and Sanitation in the Republic of Kazakhstan; UNDP: New York, NY, USA, 2006. 
5. Whittington, D.; Briscoe, J.; Mu, X.; Barron, W. Estimating the Willingness to Pay for Water Services in Developing Countries: A Case Study of the Use of Contingent Valuation Surveys in Southern Haiti. Econ. Dev. Cult. Chang. 1990, 38, 293-311.

6. Parry-Jones, S. Optimising the Selection of Demand Assessment Techniques for Water Supply and Sanitation Projects; Final Report; London School of Hygiene and Tropical Medicine, UK WEDC, Loughborough University: London, UK, 1999.

7. Anand, P.B.; Perman, R. Preferences, Inequity and Entitlements: Some issues from a CVM study of water supply in Madras, India. J. Int. Dev. 1999, 11, 27-46.

8. Briscoe, J.; Whittington, D.; Altaf, M.A.; Decastro, P.F.; Griffin, C.; Okorafor, A.; Smith, V.K. The demand for water in rural-areas determinants and policy implications. World Bank Res. Obs. 1993, 8, 47-70.

9. Davis, J.; Whittington, D. "Participatory" research for development projects: A comparison of the community meeting and household survey techniques. Econ. Dev. Cult. Chang. 1998, 47, 73-94.

10. MacGranahan, G.L.; Leitmann, J.; Surjadi, C. Understanding environmental problems in disadvantaged neighbourhoods: Broad spectrum surveys, participatory appraisal and contingent evaluation. Environ. Urban. 1997, 9, 328-328.

11. Griffin, C.C.; Briscoe, J.; Singh, B.; Ramasubban, R.; Bhatia, R. Contingent valuation and actual behavior-Predicting connections to new water-systems in the State of Kerala, India. World Bank Econ. Rev. 1995, 9, 373-395.

12. Department for International Development (DFID). DFID Guidance Manual on Water Supply and Sanitation Programmes; WELL Resource Centre: London, UK, 1998.

13. Whitehead, J.C.; Pattanayak, S.K.; van Houtven, G.L.; Gelso, B.R. Combining revealed and stated preference data to estimate the nonmarket value of ecological services: An assessment of the state of the science. J. Econ. Surv. 2008, 22, 872-908.

14. Whittington, D. Improving the performance of contingent valuation studies in developing countries. Environ. Resour. Econ. 2002, 22, 323-367.

15. Carson, R.; Flores, N.E.; Hanemann, W.M. Sequencing and valuing public goods. J. Environ. Econ. Manag. 1998, 36, 314-323.

16. Whittington, D.; Lauria, D.T.; Wright, A.M.; Choe, K.; Hughes, J.A.; Swarna, V. Household Demand for Improved Sanitation Services in Kumasi, Ghana-A Contingent Valuation Study. Water Resour. Res. 1993, 29, 1539-1560, doi:10.1029/93wr00184.

17. Dickie, M. Defensive behavior and damage cost methods. In The Economics of Non-Market Goods and Resources: A Primer on Nonmarket Valuation; Champ, P., Boyle, K., Brown, T., Eds.; Kluwer Academic Publishers: Dordrecht, The Netherlands, 2003; pp. 395-444.

18. Smith, V.K. Household production functions and environmental benefit estimation. In Measuring the Demand for Environmental Quality; Braden, J.B., Kolstad, K.D., Eds.; Elsevier Science Publishers B.V.: North-Holland, The Netherlands, 1991; pp. 388-425.

(C) 2015 by the authors; licensee MDPI, Basel, Switzerland. This article is an open access article distributed under the terms and conditions of the Creative Commons Attribution license (http://creativecommons.org/licenses/by/4.0/). 